\title{
A rare case of late atypical post-partum eclampsia
}

\author{
Sanjay Singh*, Raju Agarwal
}

Department of Obstetrics \& Gynaecology, Armed Forces Medical College, Pune, Maharashtra, India

Received: 07 August 2015

Accepted: 02 September 2015

\author{
*Correspondence: \\ Dr. Sanjay Singh, \\ E-mail: drsanjaysingh@gmail.com
}

Copyright: (C) the author(s), publisher and licensee Medip Academy. This is an open-access article distributed under the terms of the Creative Commons Attribution Non-Commercial License, which permits unrestricted non-commercial use, distribution, and reproduction in any medium, provided the original work is properly cited.

\begin{abstract}
Atypical post-partum eclampsia though uncommon is a recognized entity. Here we are presenting a case that developed postpartum eclampsia on day four of delivery without any preceding signs and symptoms of preeclampsia. Keeping this entity in mind would not only help early detection and appropriate institution of management but would also save the patients undergoing unnecessary treatment for a long period of time. This is more relevant for developing country like ours where eclampsia is an important cause of maternal mortality and resources for management of such cases are limited.
\end{abstract}

Keywords: Atypical postpartum eclampsia, Late postpartum eclampsia, Eclampsia

\section{INTRODUCTION}

Traditionally eclampsia is development of convulsions and/or unexplained coma at more than 20 weeks gestation and /or less than 48 hours after delivery. ${ }^{1}$ In case if eclampsia occurs before 20 weeks or after 48 hours postpartum or in absence of typical signs of hypertension and/or proteinuria, it is called atypical eclampsia. ${ }^{2}$ Diagnosis and management of these cases is a challenge for obstetricians. ${ }^{3}$ Here we present a case of late atypical postpartum eclampsia.

\section{CASE REPORT}

A 22 years old primigravida had full term vaginal delivery at 39 weeks period of gestation. A $2.6 \mathrm{~kg}$ male baby was born with normal APGAR. She was a booked case with regular antenatal visits. She had no high risk factors during antenatal period. She was normotensive throughout the antenatal and intra partum period. Her blood group was $\mathrm{AB}$ positive. She was euglycaemic and screening tests for HIV, Hepatitis B, C and Syphilis were negative. Urine test done four weeks prior to delivery was normal. Post-partum period was uneventful till day three.

On the day of discharge i.e. on fourth post-partum day she had an episode of generalized tonic clonic seizure preceded by mild headache and nausea. Examination of the patient two hours after the seizure revealed GCS of 13/15 (E4V4M5), blood pressure of 100/60 mm of $\mathrm{Hg}$ and normal temperature. Cardiovascular system and respiratory system were normal. Uterus was involuting and was non-tender. There were no signs of meningeal irritation or sensory motor deficit. All the peripheral reflexes were normal and bilateral plantar suggested flexor response. There was no papilloedema. Laboratory work up including complete blood count, serum electrolyte, renal functions test, liver functions test, coagulation profile, blood sugar, serum calcium and magnesium were all normal. Peripheral blood smear ruled out haemolysis. However urine for protein done with the urostrip for protein was $1+$ and 24 hours urinary protein was $330 \mathrm{mg} / \mathrm{dl}$. Screening for SLE and Anti Phospholipid Syndrome was negative. CSF study done after stabilization of the patient was normal. MRI and EEG were normal. ECG done on the same day was also normal.

The patient was diagnosed as a case of atypical late postpartum eclampsia and was managed with magnesium sulphate as per Pritchard's regime apart from supportive care. She responded to treatment and had no fresh episodes of seizure. Magnesium sulphate was continued for 24 hours post seizure. She was kept under observation 
for seven more days, during which she remained asymptomatic. She remained asymptomatic during her post natal visits too. Urinary protein was negative after four weeks from the day of seizure.

\section{DISCUSSION}

Convulsion in a setting of preeclampsia after 20 weeks of gestation till 48 hours postpartum is known as Eclampsia and is a well-known entity. Diagnosis in these cases is obvious. Occurrence of Eclampsia before 20 weeks or after 48 hours postpartum or in absence of typical signs of hypertension and/or proteinurea, is known as atypical eclampsia. Late post-partum eclampsia (occurring after 48 hours postpartum but within 4 weeks after the delivery) is a rare variant and late post-partum eclampsia occurring without preceding preeclampsia is even rarer and invariably poses diagnostic dialemma. ${ }^{3}$

Our patient did not have any signs and symptoms of preeclampsia during antenatal period as well as first 72 hours of postpartum period, though her complaints of mild headache and nausea preceded generalized tonic clonic convulsions. Our diagnosis of atypical delayed postpartum eclampsia was based on clinical presentation, biochemical finding and exclusion of other underlying disorders. Possible differential diagnosis of eclampsia includes cerebrovascular accidents (haemorrhage, arterial embolism or thrombosis, cerebral venous thrombosis, hypoxic ischemic encephalopathy, angiomas) hypertensive encephalopathy, seizure disorder, undiagnosed brain tumours, metastatic gestational trophoblastic disease, metabolic disease, reversible posterior leukoencephalopathy syndrome, antiphospholipid antibody syndrome, thrombotic thrombocytopenic purpura and cerebral vasculitis. All were excluded in our case by relevant investigations. Our case thus highlights the fact that any prodromal symptom e.g. headache during post-partum period in spite of absence of preceding hypertension and or proteinuria, should alert the physician and cast suspicion on impending eclampsia

As per Adie et al. out of 162 cases of Eclampsia encountered during a period of 2 years, $8 \%$ had features of atypical eclampsia with normal blood pressure. ${ }^{4}$ Katz et al. reported 53 cases of eclampsia wherein there was no preceding preeclampsia and seizure was the only manifestation of the disease..$^{5}$ Out of 54 cases of eclampsia (over15 years) Lubarsky et al. noted that $44 \%$ cases had no feature of prior preeclampsia. ${ }^{6}$

Presently there is no standard guideline for early detection and prevention of late onset post-partum eclampsia in a patient without prior preeclampsia. It has been found that these patients can have symptoms of brain oedema (headache, visual symptoms) even when they are normotensive as it is highlighted from our case. ${ }^{7}$
In a retrospective study Atterbury JL et al. noted that neurological complaints, malaise, nausea and vomiting were reported more often in women with post-partum preeclampsia than antepartum preeclampsia. ${ }^{8}$ Thus postpartum development of these symptoms should be given due importance and regular monitoring of blood pressure and haematological and biochemical parameters should be done, for the timely detection of post-partum preeclampsia/eclampsia.

\section{CONCLUSION}

Late postpartum eclampsia without any prior evidence of preeclampsia is an established rare entity. It has been found that many of these patients develop neurological symptoms, malaise, nausea and vomiting prior to development of eclampsia. Aim of presenting this case is to highlight this rare entity and also to emphasize the importance of neurological symptoms which may be the only presentation prior to a seizure. One must be careful not to misdiagnose this as seizure disorder unrelated to pregnancy though it occur late. ${ }^{9}$

\section{Funding: No funding sources \\ Conflict of interest: None declared \\ Ethical approval: Not required}

\section{REFERENCES}

1. Sibai BM. Diagnosis, prevention and management of eclampsia. Obstet Gynecol. 2005;105:402-10.

2. Sibai BM, Stella CL. Diagnosis and management of atypical preeclampsia eclampsia. Am J Obstet Gynecol 2009; 200:481.e1-481.e7.

3. Santosh VM, Correa FG, Modesto FR et al. Late onset postpartum eclampsia-Still a diagnostic dilemma. Hong Kong med J.2008;14:60-3.

4. Adie V. Moodley J. Atypical Eclampsia. J Obstet Gynecol. 2005;25:352.

5. Nirromaneshe S, Mizale F. Atypical post-partum eclampsia: status epilepticus without preeclamptic prodromi. Women Birth. 2008:21:171-3.

6. Lubarsky SL, Barton JR, Friedman SA et al. Late post-partum eclampsia revisited. Obstet Gynecol 1994;83:502-5.

7. Veltkamp R, Kupsch A, Polasek J, et al. Late onset post-partum eclampsia without pre eclamptic prodromi: clinical and neurological presentation in two patients. J of Neurol Neurosurg Psychiatry. 200;69:824-27.

8. Atterbury JL, Groome LJ, Hoff $\mathrm{C}$ et al. Clinical presentation of women readmitted with post-partum severe preeclampsia or eclampsia. J of Obstet Gynecon Neonatal Nurse. 1998;27:134-41

9. Mathew R, Raj RS, Sudha P et al. Late post-partum eclampsia without prodroma. Neuro India (Serial Online) 2003. (Cited 2015 Jun 7);51:539-40.

Cite this article as: Singh S, Agarwal R. A rare case of late atypical post-partum eclampsia. Int J Reprod Contracept Obstet Gynecol 2015;4:1645-6. 